\title{
THE CYCLIC BEHAVIORS OF BOX-SECTION STEEL BEAM-COLUMNS: EXPERIMENT AND NUMERICAL COMPARISON
}

\author{
Ming-zhou $\mathrm{Su}^{1, *}$, Lin $\mathrm{Shen}^{2}$, Qiang $\mathrm{Gu}^{3}$ \\ ${ }^{I}$ School of Civil Engineering, Xi'an University of Architecture \& Technology, Xian, 710055, China \\ *(Corresponding author: E-mail: sumingzhou@163.com) \\ ${ }^{2}$ China Institute of Building Standard Design and Research, Beijing, 100044, China \\ ${ }^{3}$ University of Science and Technology of Suzhou, Suzhou, 215011, China
}

\begin{abstract}
A series of tests were performed to evaluate the cyclic behaviors of box-section steel beam-columns under cyclic bending. The test was set up as a cantilever beam-column, loaded with cyclic transverse shear force at its free end, while the axial compression kept unchanged. Three sets of tests with various axial compression ratios were tested to find out their influencing on cyclic behaviors, which were $0.0,0.4$ and 0.6 , respectively. In each set, there were five members with various width-to-thickness ratios of plates to consider their effects. The hysteretic curves and failure mechanisms of each member were given according the test results, and the main influencing factors, such as axial compression ratio of the member, width-to-thickness ratio of its plates, were analyzed. Then, the test results were compared with that of numerical analysis by the author. In general, there was a good agreement between two results, it revealed that the numerical analysis was reasonable and could be used in practice.
\end{abstract}

Keywords: Beam-column; Cyclic bending; Experiment; Numerical analysis; Hysteretic behavior; Box-section.

\section{INTRODUCION}

High-rise building will not only undergo the gravity static loads, but also the dynamic horizontal actions, such as earthquake and wind action. In general, the latter becomes more important with the increase of building's height. In this case, the columns are subjected to large unchanged axial compression and varied bending moment. As the inflection point of columns generally lies near its mid-height, the problem can be simplified as a cantilever subjected to cyclic transverse shear at its free end, while the axial compression kept unchanged. For the facility of analysis, most researchers simplified the various action as a qusa-static manner, i.e., cyclic loading.

In the early 1969s, Kato [1] established the cyclic curve of beam-columns under cyclic bending. In his model, the relationship of moment-curvature was built based on monotonic loading, and the material was assumed to follow rigid plastic hardening, so the model was inaccurate and overestimated the bearing capacity of the member.

Toma and Chen [2] and Han and Chen [3] discussed the response of beam-columns under cyclic bending. Many simplifications were introduced in the analysis to get a closed-form solution, so only one or less cycle could be performed, the behavior of members could not be predict after several cycles.

Billio and Calado [4] carried out an experiment on beams under cyclic bending. The phenomenon of capacity deterioration of beams was found in case of local buckling occurred in their study. Furthermore, a simplified numerical model was established to consider the effect of local buckling and fracture on the capacity deterioration.

Macrae [5] performed an experiment on beam-columns under cyclic bending with constant or various axial compressions. The aim of the test was to investigate the influence of axial force on the behavior of beam-columns. It noted that the results on few tests were not reliable, and the limitation of axial force would not be relaxed before thorough analysis. 
Watanable [6] put forward a simplified model to study the cyclic behavior of beam-columns with square hollow section. In that model, the section was divided into many fibers, each fiber was assumed to follow uniaxial stress state, perfect elastic-to-plastic material was assumed, and the residual stress and initial geometric imperfection were not considered.

Hao [7] studied the cyclic behavior of beam-columns with H-shaped sections. The simplified plastic zone model was adopted in his numerical analysis, and the plastic damage accumulation was considered. But the critical factors in the model were based on experimental results and varied with each member, so it could not be used to predict the behavior of members untested.

Yamazaki and Minami [8] performed experiment and numerical analysis on box-section beam-columns under various axial force and cyclic bending. In their analysis, the plane section hypothesis was used, and the one-dimensional hysteretic model of Ohi et al. [9] was adopted. As a result, they found the transverse resistance of the member decreased dramatically with large axial compression, and the strength was between that of cyclic bending with constant maximum axial compression and that with minimum axial compression.

Miki and Nethercot [10] built up a multi-failure mechanism numerical model of beam-columns with varied cross-section. It found that two failure mechanisms would appear alternatively in one cycle, and the member would then lose its stability.

Gao et al. [11] performed a finite element analysis on the ultimate strength and ductility capacity correlation between centrally loaded and eccentrically loaded columns subjected to cyclic transverse load. Both geometrical and material nonlinearity was considered in the analysis, and a modified two-surface plasticity model is employed to model material nonlinearity. As a result, equations were proposed to evaluate the ultimate strength and ductility capacity of the eccentrically loaded columns from those of the centrally loaded columns.

To analysis the behavior of steel beam-columns under cyclic bending, the author $[12,13]$ suggested a numerical method based on degenerated shell element, together with the updated Lagrange formulation and the mixed hardening material. As a result, the author gave suggestions about the limit of width-to-thickness ratio of plates and the bearing capacity of members.

In order to evaluate the hysteretic behavior of box-section steel beam-columns under cyclic bending, a series of tests was carried by the author. This paper contains a description of test specimens, set-up and instrumentation, procedure, and results. A comparison of the experimental and analytical results is also provided.

\section{TEST SPECIMENS}

A series of three group tests was conducted, corresponding with various axial compression ratios, which were 0.0, 0.4 and 0.6, respectively. Each of the three groups contained five members with various width-to-thickness ratios of their plates. These specimens were welded by hand-arc welds with E43 electronic rod, and the material of their plates is Q235B. The test was set up as a cantilever beam-column, loaded with cyclic transverse shear force at its free end, while the axial compression kept unchanged. The test was controlled by the transverse displacement at the free end. The configuration of specimens and loading scheme were described in Figure 1 and Table 1. 
Table 1. Configuration of Specimens

\begin{tabular}{|c|c|c|c|c|c|c|c|c|c|c|}
\hline \multirow{2}{*}{ Item } & \multirow{2}{*}{$h / t_{w}$} & \multirow{2}{*}{$b / t_{f}$} & \multirow{2}{*}{$\begin{array}{c}h \\
(\mathrm{~mm})\end{array}$} & \multirow{2}{*}{$\begin{array}{c}b \\
(\mathrm{~mm})\end{array}$} & \multirow{2}{*}{$\begin{array}{l}t_{f}, t_{w} \\
(\mathrm{~mm})\end{array}$} & \multirow{2}{*}{$N / A f_{y}$} & \multirow{2}{*}{$\begin{array}{c}\delta_{\mathrm{y}} \\
(\mathrm{mm})\end{array}$} & \multicolumn{3}{|c|}{ Displacements (mm) } \\
\hline & & & & & & & & $\delta_{1}$ & $\delta_{2}$ & $\Delta$ \\
\hline S-1-0 & 23.0 & 19.0 & 92 & 76 & 4 & 0.0 & 9.81 & 10 & 20 & 10 \\
\hline S-2-0 & 33.3 & 23.5 & 133 & 94 & 4 & 0.0 & 6.79 & 7 & 10 & 10 \\
\hline S-3-0 & 33.5 & 29.0 & 134 & 116 & 4 & 0.0 & 6.74 & 7 & 10 & 10 \\
\hline S-4-0 & 43.3 & 29.0 & 173 & 116 & 4 & 0.0 & 5.22 & 5 & 10 & 10 \\
\hline S-5-0 & 43.5 & 36.0 & 174 & 144 & 4 & 0.0 & 5.19 & 5 & 10 & 5 \\
\hline S-1-4 & 23.8 & 19.0 & 95 & 76 & 4 & 0.4 & 5.70 & 6 & 10 & 10 \\
\hline S-2-4 & 33.3 & 23.5 & 133 & 94 & 4 & 0.4 & 4.07 & 4 & 5 & 5 \\
\hline S-3-4 & 33.5 & 29.0 & 134 & 116 & 4 & 0.4 & 4.04 & 4 & 5 & 5 \\
\hline S-4-4 & 43.3 & 29.0 & 173 & 116 & 4 & 0.4 & 3.15 & 3 & 5 & 5 \\
\hline S-5-4 & 43.5 & 36.0 & 174 & 144 & 4 & 0.4 & 3.14 & 3 & 5 & 5 \\
\hline S-1-6 & 23.0 & 19.0 & 92 & 76 & 4 & 0.6 & 3.96 & 4 & 5 & 2.5 \\
\hline S-2-6 & 33.5 & 23.5 & 134 & 94 & 4 & 0.6 & 2.72 & 3 & 5 & 2.5 \\
\hline S-3-6 & 33.5 & 29.0 & 134 & 116 & 4 & 0.6 & 2.72 & 3 & 5 & 2.5 \\
\hline S-4-6 & 44.0 & 29.0 & 176 & 116 & 4 & 0.6 & 2.08 & 2 & 5 & 2.5 \\
\hline S-5-6 & 43.5 & 36.0 & 174 & 144 & 4 & 0.6 & 2.11 & 2 & 5 & 2.5 \\
\hline
\end{tabular}

Note: i. $h$ and $b$ are the height and the width of the cross-section, and $t_{\mathrm{w}}$ and $t_{\mathrm{f}}$ are the thickness of its web and flange, respectively.

ii. $N / A f_{\mathrm{y}}$ is the axial compression ratio.

iii. $\delta_{\mathrm{y}}$ is the transverse displacement when the extreme fiber at the fix end of the member yields.

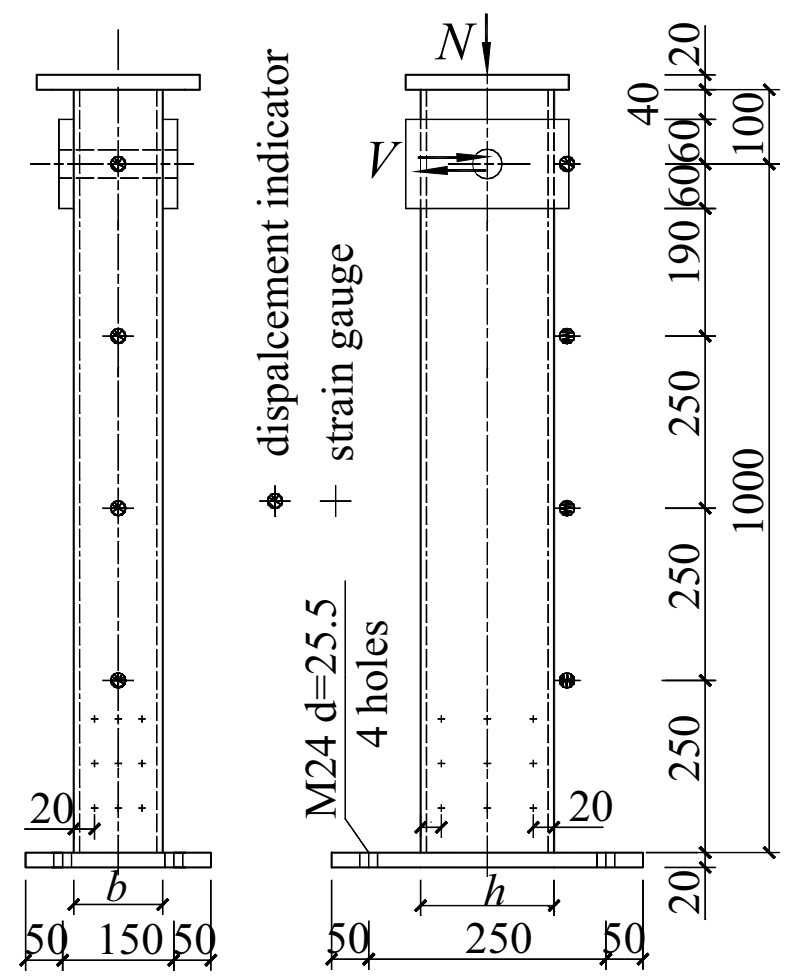

Figure 1. Configuration of Specimens 


\section{TEST SET-UP AND TEST PROCRDURE}

Test set-up was shown in Figure 2. The specimen (1) was fixed on the floor girder (2) through 4 high-strength bolts (3), the diameter of which are $24 \mathrm{~mm}$, with the material grade of $10.9 \mathrm{~S}$ (the tensile ultimate strength of the material is $1040 \mathrm{~N} / \mathrm{mm}^{2}$, and the yield strength is $940 \mathrm{~N} / \mathrm{mm}^{2}$ ). The tested member was subjected to transverse cyclic load applied trough horizontal actuator (4), while a constant compressive load applied by vertical jack (5), which was free to move laterally in-plane on greased roller bearings (6). The jacks were fastened in the test rig (7). To prevent lateral-torsional buckling of the tested member, a lateral support (8) was provided.

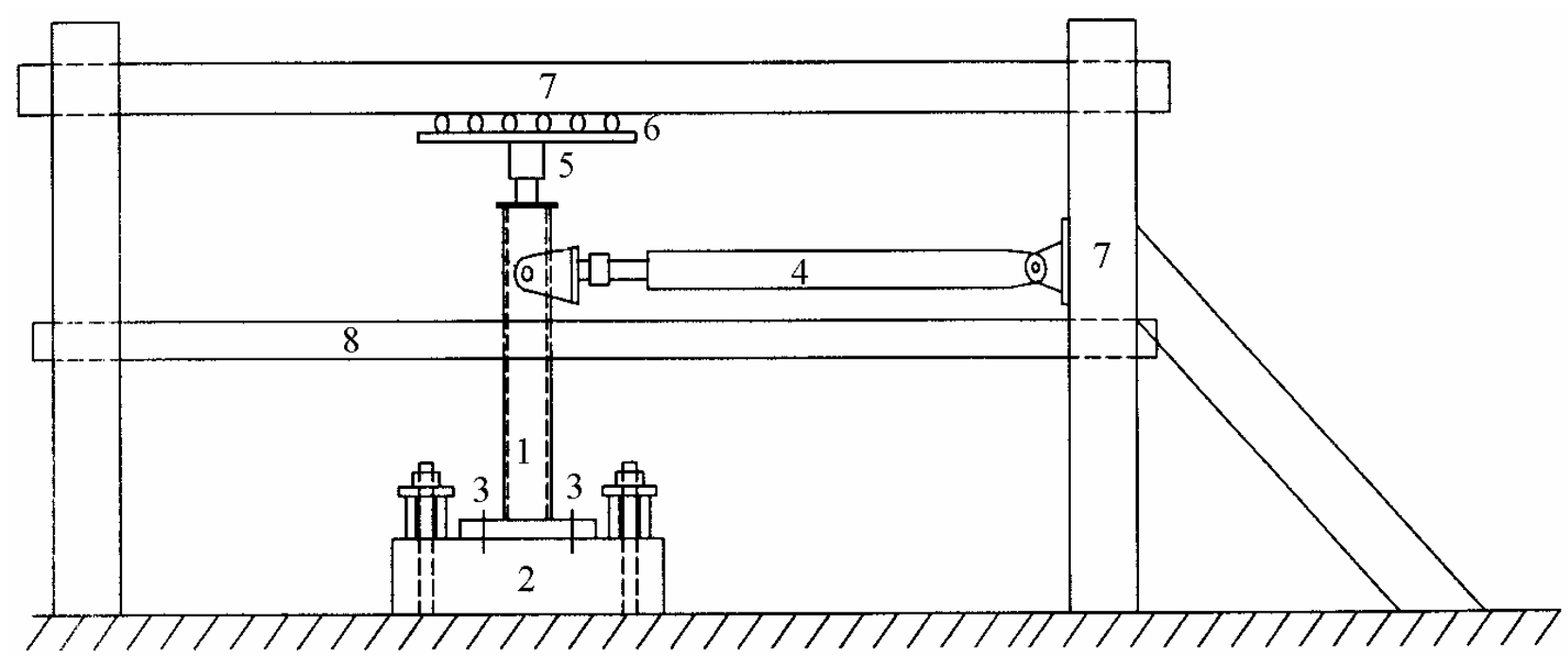

Figure 2. Test set-up

The following procedure was used to obtain accurate and reliable results of each specimen:

1. The specimen was set into position and connected to the floor girder.

2. Jacks were mounted, connected, and aligned in order to prevent eccentricity.

3. The axial compression was applied to the beam-column by vertical jack according to design.

4. The cyclic transverse displacements were applied according ECCS loading scheme. The displacement of first step was about $\delta_{1} / 2$ for one cycle as the member stayed in elastic state, and then displacement of $\delta_{1}$ and $\delta_{2}$ were applied for three cycles for some fibers of member yielded, after that an incremental displacement of $\Delta$ was added to the former step for three cycles $\left(\delta_{1}, \delta_{2}\right.$ and $\Delta$ were shown in Table 1$)$.

5. Test stopped when the specimen fractured or its bearing capacity dropped below $80 \%$ of the maximum.

\section{TEST RESULTS AND DISCUSSION}

\subsection{Results of Coupon Test}

The coupon was designed according to the demand of Chinese National Standard Metallic materials - Tensile testing at ambient temperature (GB228-2002). Based on the testing results, the material Q235B used in the experiment had the following characteristic values: Yong's modulus $E=2.05 \times 10^{5} \mathrm{MPa}$, yield stress $f_{\mathrm{y}}=279 \mathrm{MPa}$, hardening modulus $E_{\mathrm{st}}=1.84 \% E$, hardening strain $\varepsilon_{\mathrm{st}}=1.1 \%$. 


\subsection{Test Results of Beam-Columns}

\subsubsection{Members without Axial Force $\left(N / A f_{y}=0.0\right)$}

For members without axial force, the hysteretic curves were quite smooth and plump, the ductility factor was over 7.5, which revealed that the energy dissipation was very excellent. Figure 3 to Figure 7 gave the hysteretic curves of S-1-0 to S-5-0 respectively. In these figures, the vertical axis denotes the transverse shear at the free end of the member, while the horizontal one denotes the corresponding transverse displacement at the same point and the ductility factor of the member. Except that members S-2-0 and S-3-0 failed with welds fractured at the fix end due to lack of enough weld throat, all the others failed with plastic cracks of flanges near half of the section width away from the fix end, owing to low cycle fatigue. The cracks firstly developed in the intersect lines of flanges and webs, and then expanded with the increase of cyclic load, finally the section fractured. Before failure, the slop of hysteretic curve increased with the increase of displacement due to cracks closed, obviously in the member with large width-to-thickness ratios of plates, as shown in Figures 6 and 7. Fracture of S-5-0 was shown in Figure 8. The local buckling of all the five members just occurred before fracture and the buckling deformation was very small. The hysteretic behaviors of members without axial compression were listed in Table 2.

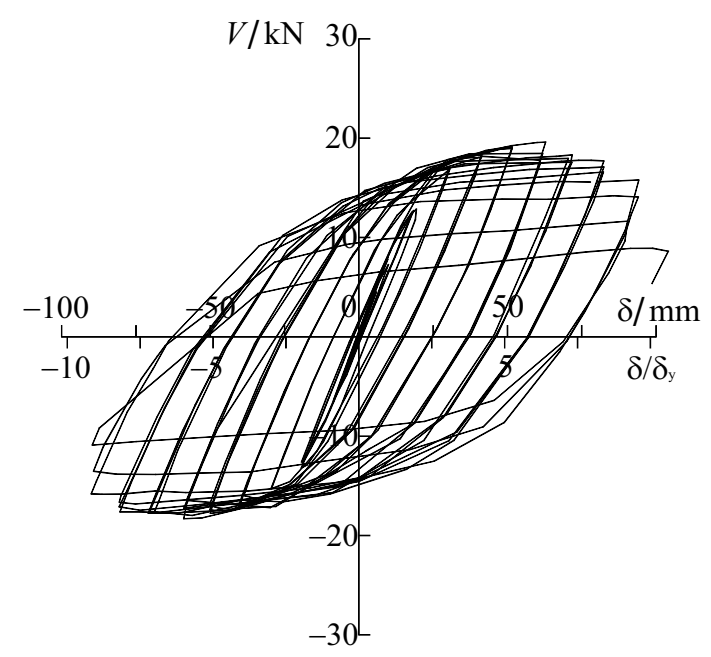

Figure 3. Hysteretic curve of S-1-0

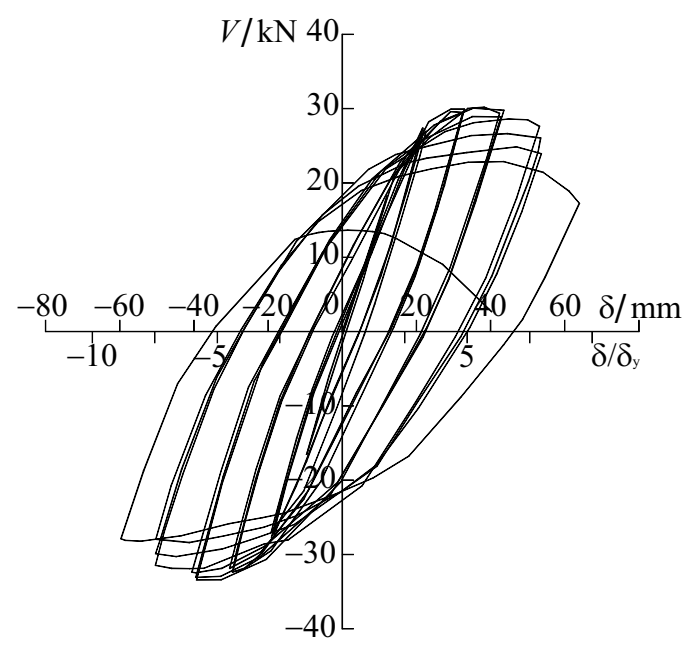

Figure 5. Hysteretic curve of S-3-0

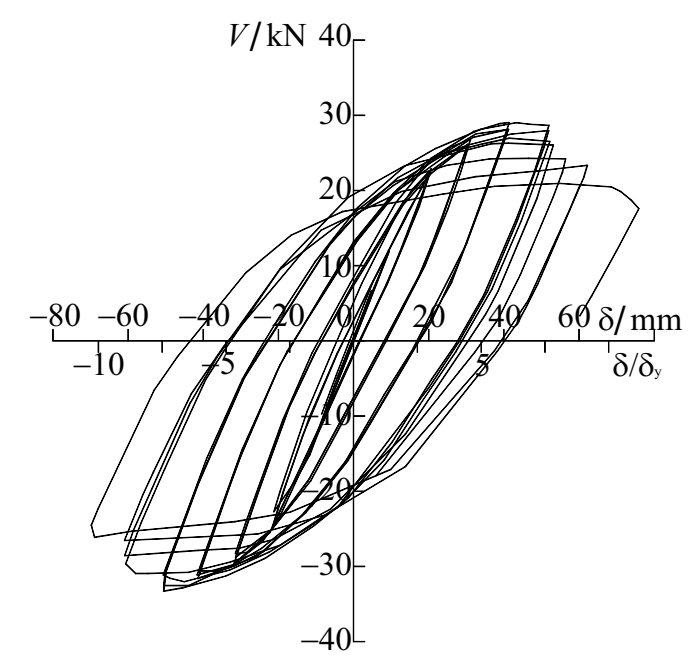

Figure 4. Hysteretic curve of S-2-0

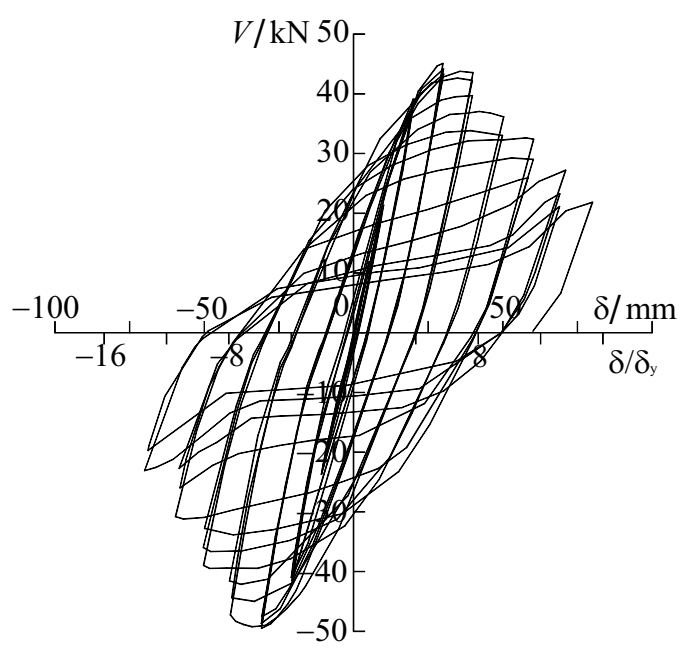

Figure 6. Hysteretic curve of S-4-0 


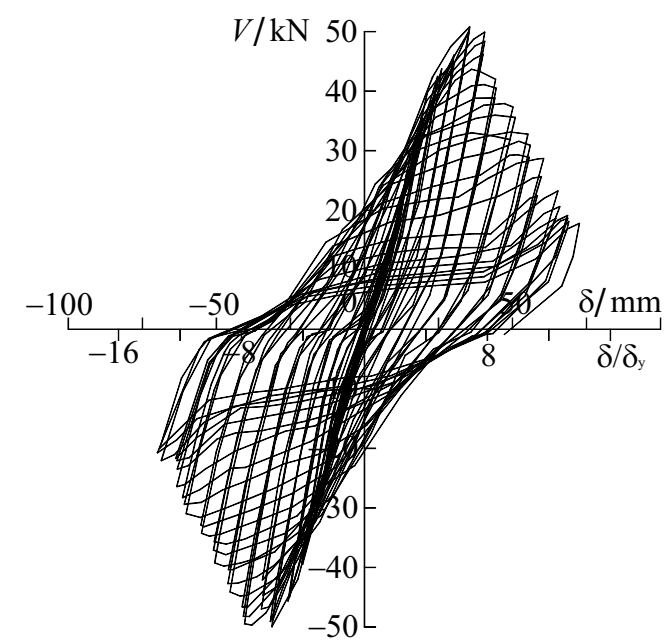

Figure 7. Hysteretic curve of S-5-0

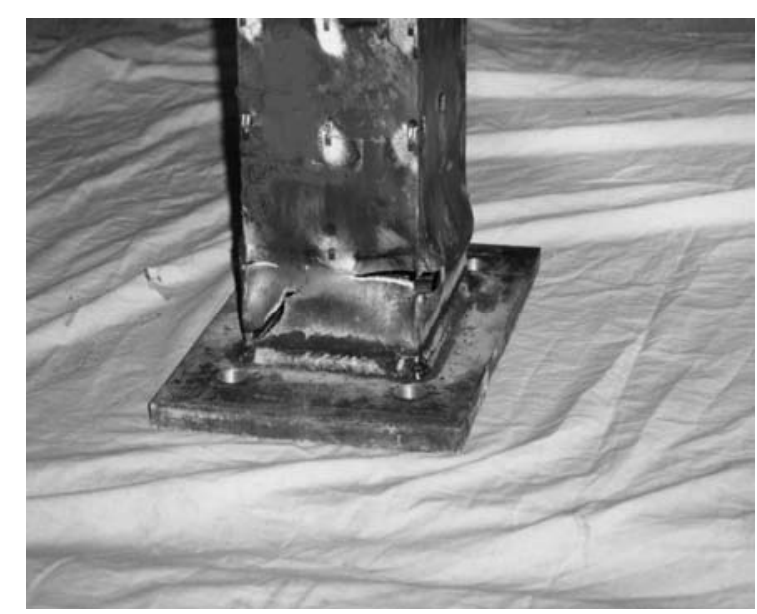

Figure 8. Fracture of member S-5-0

Table 2. The Hysteretic Behaviors of Members without Axial Force

\begin{tabular}{|c|c|c|c|c|c|}
\hline Item & S-1-0 & S-2-0 & S-3-0 & S-4-0 & S-5-0 \\
\hline Rotation angle (\%) & 9.0 & 6.0 & 5.0 & 5.0 & 5.0 \\
\hline $\begin{array}{c}\text { Ductility factor } \\
\text { b }\end{array}$ & 9.5 & 9.0 & 7.5 & 8.0 & 8.3 \\
\hline $\begin{array}{c}\text { Location of plastic } \\
\text { hinge }\end{array}$ & $0.53 b$ & $0.53 b$ & $0.47 b$ & $0.52 b$ & $0.38 b$ \\
\hline Failure mode & $\begin{array}{c}\text { Section } \\
\text { fractured }\end{array}$ & $\begin{array}{c}\text { Section cracked, but failure due to } \\
\text { welds fractured at the fix end }\end{array}$ & $\begin{array}{c}\text { Similar to } \\
\text { S-2-0 }\end{array}$ & $\begin{array}{c}\text { Similar to } \\
\text { S-1-0 }\end{array}$ & $\begin{array}{c}\text { Similar to } \\
\text { S-1-0 }\end{array}$ \\
\hline
\end{tabular}

Note: ${ }^{a}$ Rotation angle is defined as total transverse displacement $(\delta)$ over the length of the member $(l)$.

${ }^{\mathrm{b}}$ Ductility factor is termed as $\delta$ over $\delta_{\mathrm{y}}$.

\subsubsection{Members with axial compression ratio $N / A f_{y}=0.4$}

The hysteretic curves of members S-1-4 to S-5-4 were shown in Figure 9 to Figure 13, respectively. It was shown in the figure that plates of members were susceptible to buckle locally as the existence of large axial compression, and the capacities of ductility and energy dissipation were serious deteriorated owing to the local buckling. Even for the member S-1-4 with smallest plate width-to-thickness ratios, the ductility factor was only about 5. Local buckling developed in the section near the fix end with the increase of transverse shear, members failed owing to the cyclic local buckling, and no cracks were found in the section or in the welds of fix end. The members with small width-to-thickness ratios of plates failed due to dramatic decrease of bearing capacity, while ones with large with-to-thickness ratios failed due to severe local buckling. Local buckling of S-4-4 was shown in Figure 14, and hysteretic behaviors of these five members were described in Table 3. The failure mode in this Table referred to the dominant deformation of the member, Plastic referred to the failure mainly caused by plastic deformation; Local Buckling referred to the failure mainly caused by local buckling.

Table 3. The Hysteretic Behaviors of Members with Axial Compression Ratio N/Af $\mathrm{f}_{\mathrm{y}}=0.4$

\begin{tabular}{|c|c|c|c|c|c|}
\hline Item & S-1-4 & S-2-4 & S-3-4 & S-4-4 & S-5-4 \\
\hline Rotation angle (\%) & 3.0 & 2.0 & 2.0 & 1.3 & 1.0 \\
\hline Ductility factor & 5.0 & 4.8 & 4.5 & 4.0 & 3.0 \\
\hline $\begin{array}{c}\text { Location of } \\
\text { local buckling }\end{array}$ & $0.71 b$ & $0.85 b$ & $0.56 b$ & $0.93 b$ & $0.79 b$ \\
\hline Failure mode & Plastic & $\begin{array}{c}\text { Plastic, local } \\
\text { Buckling }\end{array}$ & $\begin{array}{c}\text { Plastic, local } \\
\text { Buckling }\end{array}$ & Local buckling & Local buckling \\
\hline
\end{tabular}




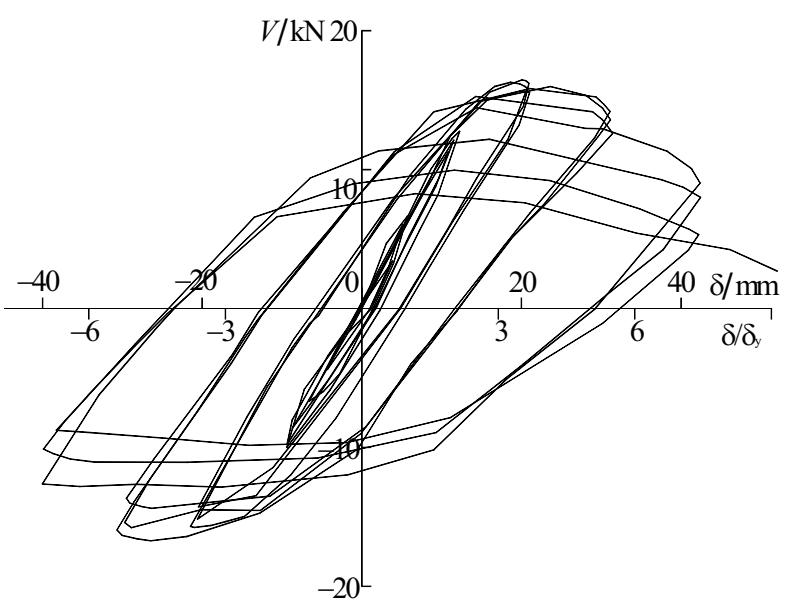

Figure 9. Hysteretic curve of S-1-4

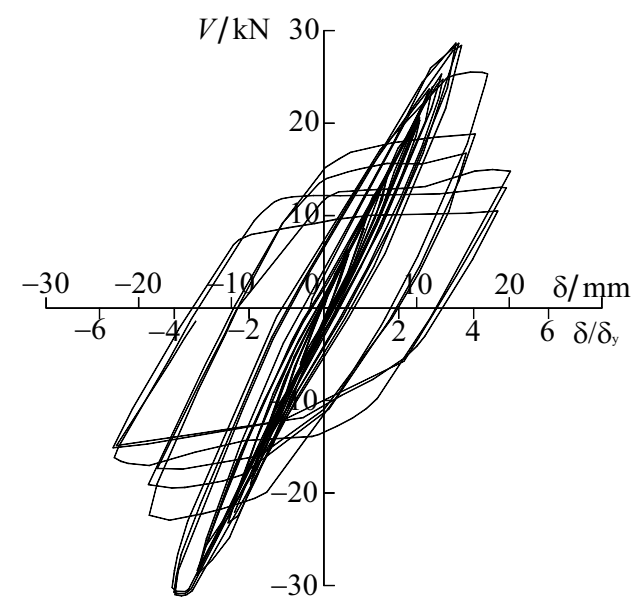

Figure 11. Hysteretic curve of S-3-4

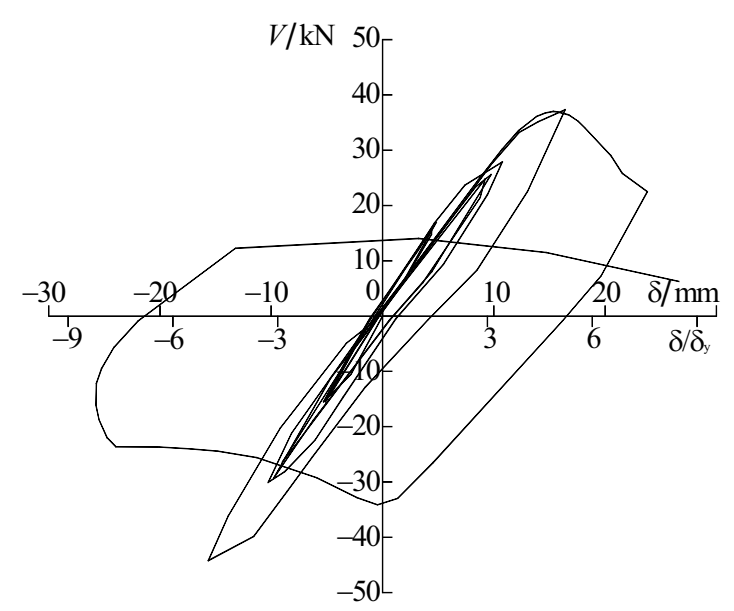

Figure 13. Hysteretic curve of S-5-4

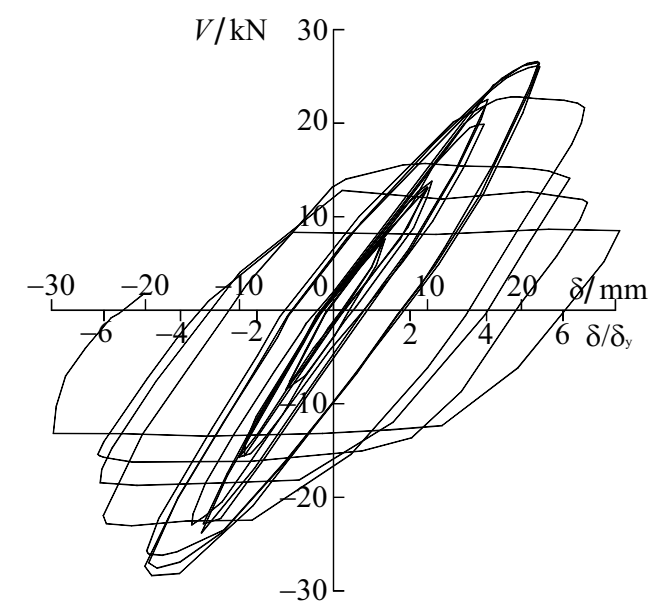

Figure 10. Hysteretic curve of S-2-4

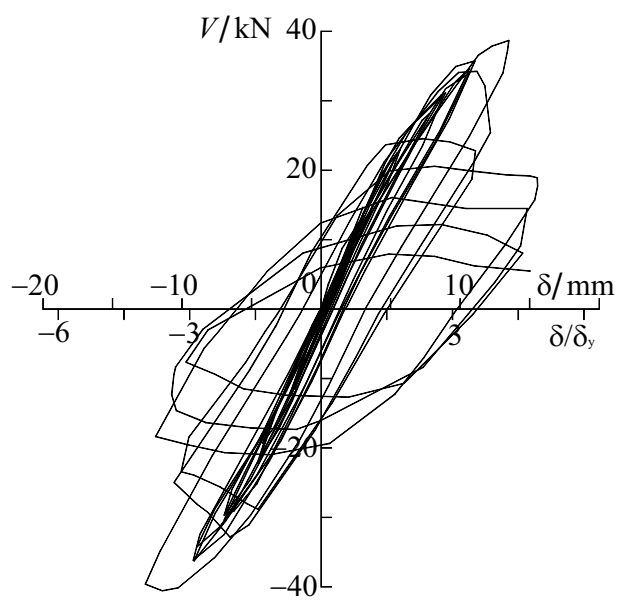

Figure 12. Hysteretic curve of S-4-4

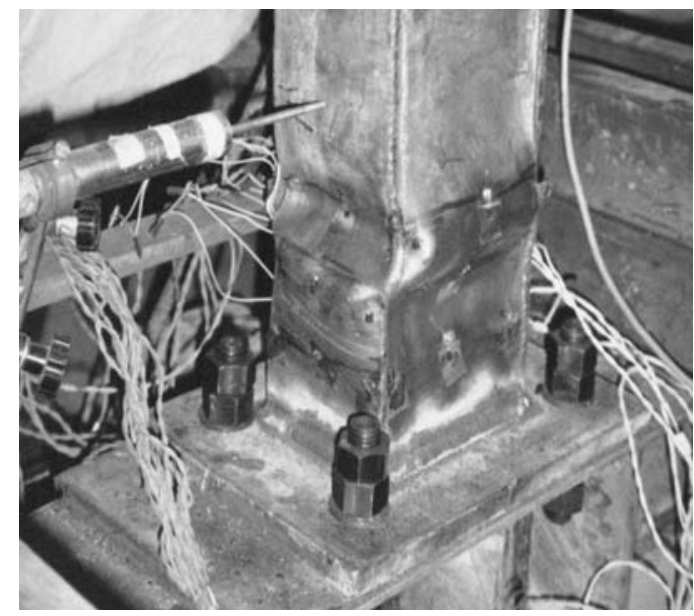

Figure 14. Local buckling of S-4-4

\subsubsection{Members with Axial Compression Ratio $N / A f_{y}=0.6$}

The ductility and bearing capacity of members with $N / A f_{y}=0.6$ deteriorated more seriously than those with $N / A f_{y}=0.4$. This phenomenon is mainly caused by severe local buckling of their plates due to the large axial compression ratio. These members failed mainly due to the local buckling. 
As soon as the bearing capacity reached, the maximum load decreased quickly with the increase of transverse displacement, brittle failure might occur in the member with large plate width-to-thickness ratio, such as S-4-6 and S-5-6. The hysteretic curves of members with axial compression ratio $N / A f_{y}=0.6$ were shown in Figures 15 to 19 . Except that S-1-6 underwent large plastic deformation, the other 4 members failed mainly due to local buckling. Figure 20 showed the local buckling of S-4-6 when failure occurred, which was similar to Figure 14. The hysteretic behaviors were listed in Table 4.

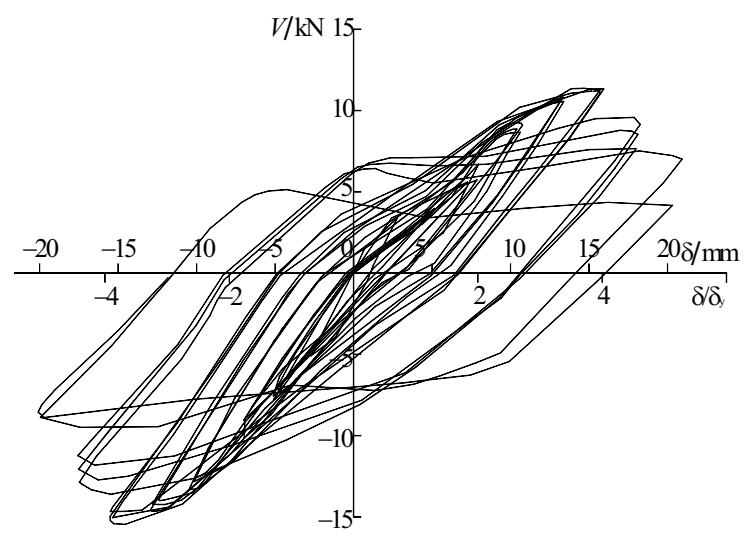

Figure 15. Hysteretic curve of S-1-6

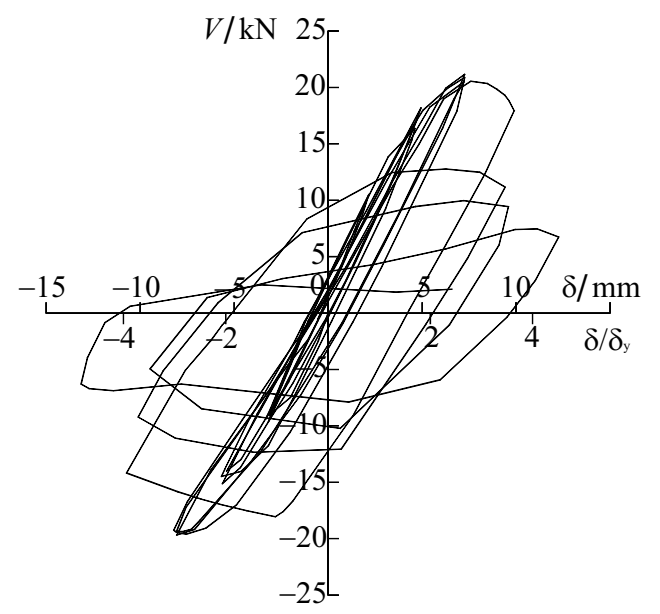

Figure 17. Hysteretic curve of S-3-6

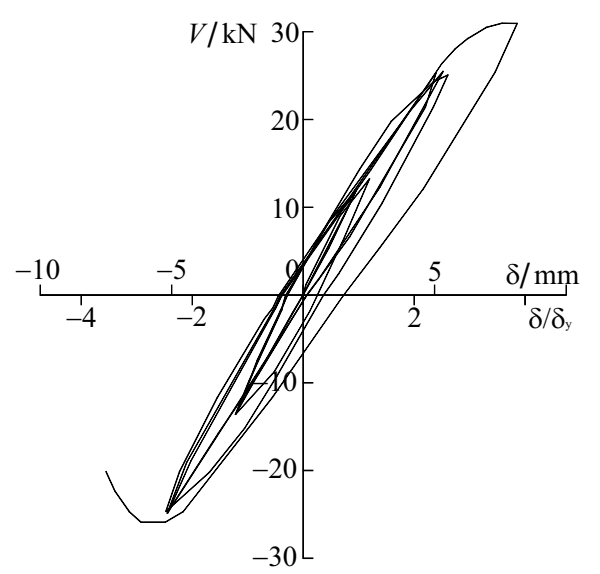

Figure 19. Hysteretic curve of S-5-6

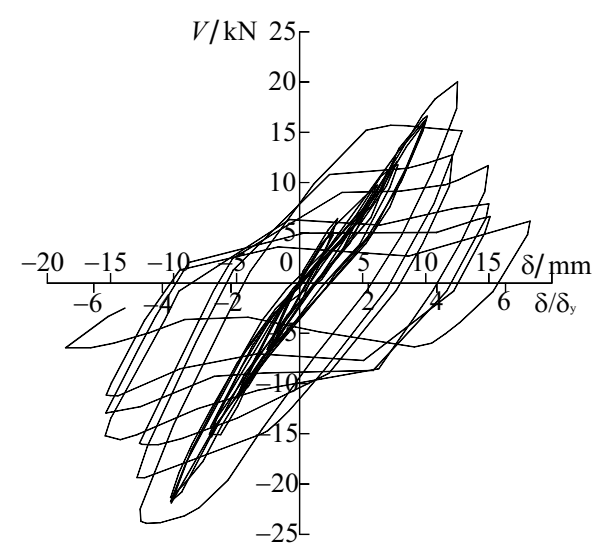

Figure 16. Hysteretic curve of S-2-6

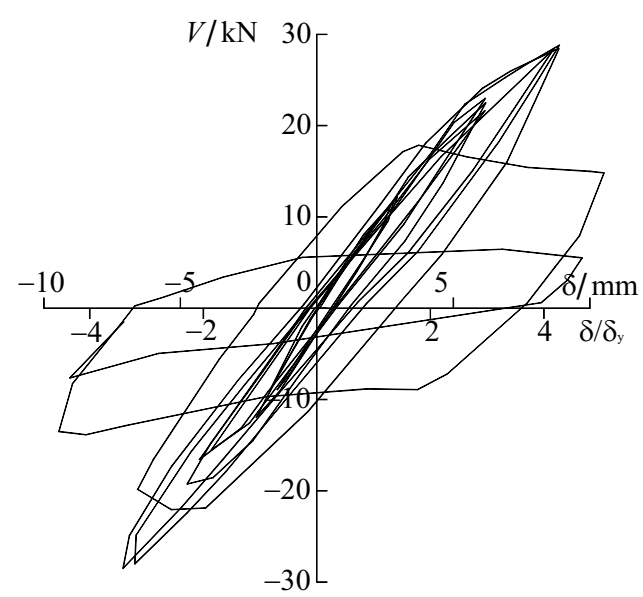

Figure 18. Hysteretic curve of S-4-6

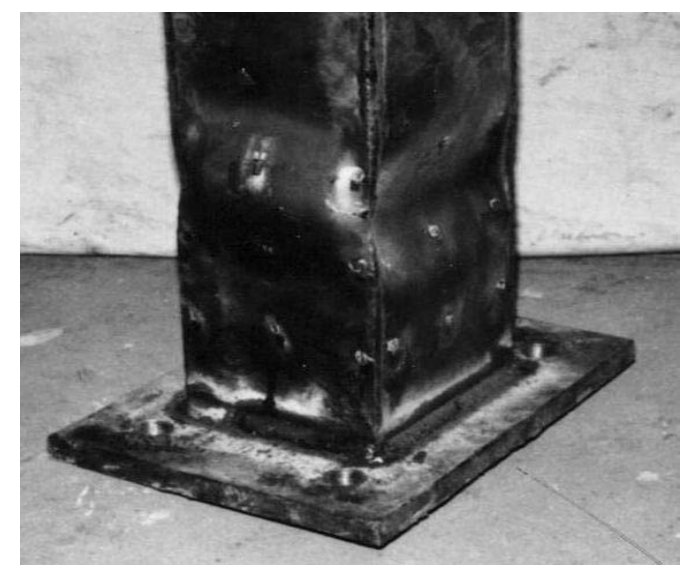

Figure 20. Local buckling of S-4-6 
Table 4. The Hysteretic Behaviors of Specimens with Axial Compression Ratio N/Af $f_{y}=0.6$

\begin{tabular}{|c|c|c|c|c|c|}
\hline Item & S-1-6 & S-2-6 & S-3-6 & S-4-6 & S-5-6 \\
\hline Rotation angle (\%) & 1.8 & 1.3 & 0.75 & 0.75 & 0.5 \\
\hline Ductility factor & 4.5 & 4.2 & 2.8 & 3.8 & 2.5 \\
\hline $\begin{array}{c}\text { Location of } \\
\text { local buckling }\end{array}$ & $0.98 b$ & $0.53 b$ & $0.56 b$ & $0.78 b$ & $1.30 b$ \\
\hline Failure mode & Plastic & $\begin{array}{c}\text { Plastic, local } \\
\text { Buckling }\end{array}$ & Local buckling & Local buckling & Local buckling \\
\hline
\end{tabular}

\section{THE COMPARISON OF EXPERIMENTAL AND NUMERICAL RESULTS}

\subsection{Comparisons of Hysteretic curves}

A degenerated shell element with eight nodal points was used for implementing the formulation. Both material and geometric non-linearity were taken into account. The program had the following characteristics: 1) Degenerated shell element assumption is adopted, i.e., the normal of the mid-surface of shell keeps straight after deflection, but no longer keeps normal. 2) The virtual work equation is expressed in terms of updated Lagrange formulation. 3) The plastic flow theory is applied considering the Mises' yield function as a plastic potential. 4) The material is assumed to follow the mixed hardening law, which linearly combines isotropic and kinematic hardening. Details can be found in the reference [13].

Based on the numerical analysis, the calculated curves of S-3-4 and S-4-6 were shown in Figure 21 and Figure 22 respectively. By comparing of Figure 21 with Figure 11 and Figure 22 with Figure 18, it was shown that the bearing capacity, deterioration rate of maximum load and ductility

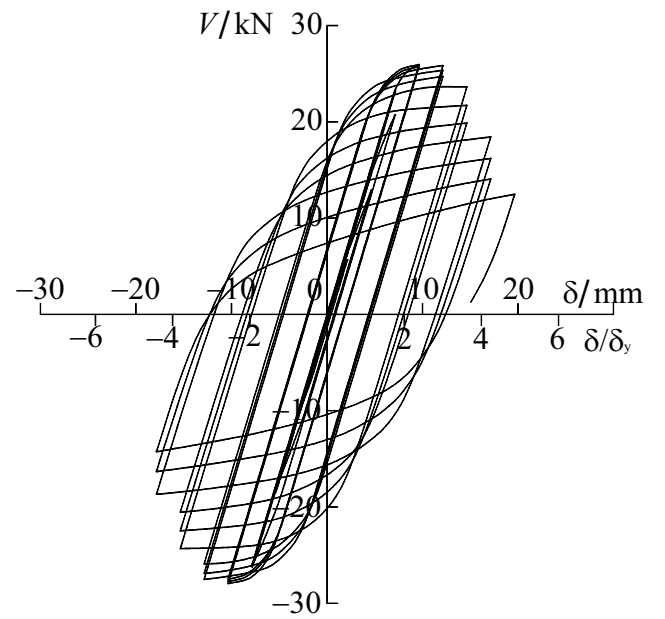

Figure 21. Numerical curve of S-3-4

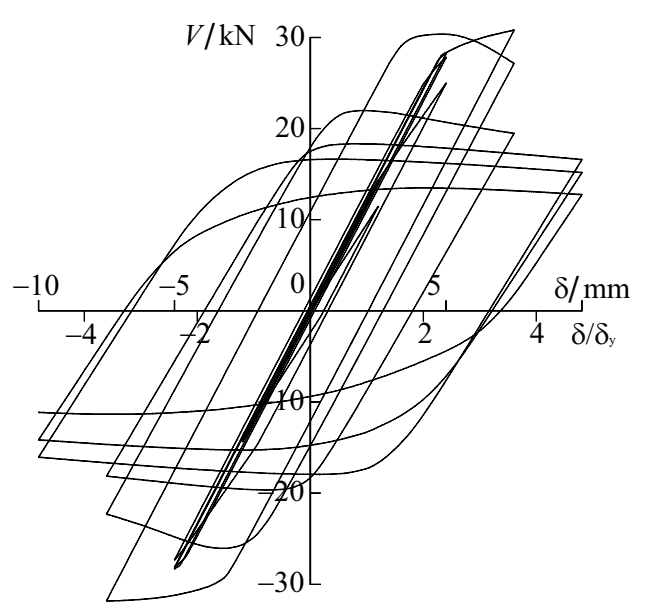

Figure 22. Numerical curve of S-4-6

factor of both curves were very close, so there was a good agreement between two results. However, there was an obvious deference in stiffness that the experimental one was lower than that of calculating, and the experimental curve was not as plumb as that of calculating. This was mainly due to the following reasons:

1. Only the welded residual stress along the longitudinal axial was considered in numerical analysis. As the thick end-plate was welded to the member, the distribution of residual stress in the end was very complex, it might have large influencing on the stiffness of the member, but it was very difficult to simulate and was not considered in the numerical analysis. 
2. As the member was anchored to the floor beam by four high-strength bolts, the rotation of fix end could not be avoid, the bolts would loosen when many cycles repeated, this would decrease the stiffness of the member, and it was not considered in calculation.

3. Only initial deflection was considered in numerical analysis, the eccentricity of axial load was no to be taken into account, and this was unavoidable in experiment.

\subsection{Verification of Interrelation of Bending Moment and Axial Compression}

Eq. 1 gave the interrelation of non-dimensional bending moment and axial compression $\left(M / M_{P}-N / N_{P}\right)$, which was put forward by the author through numerical analysis [12]. The parameter $a$ in Eq. 1 could be taken as 1.10 for box-section steel beam-columns. The comparison of test data with Eq. 1 was given in Figure 23. The test data fully lay above the curve, so it was safety to use this equation. Eq. 2 could be used in practice according to Chinese Code for Design of Steel Structures GB50017-2003, in which plastic adoption $\gamma_{x}$ (only part of plastic deformation considered) equal to $1.05 \times a=1.16$ might be adopted ( 1.05 is the original plastic adoption in this Code).

$$
\begin{aligned}
& N / N_{\mathrm{P}}+M /\left(a M_{\mathrm{p}}\right)=1 \\
& \frac{N}{\varphi_{\mathrm{x}} A}+\frac{\beta_{\mathrm{mx}} M}{\gamma_{\mathrm{x}} W_{\mathrm{x}}\left(1-0.8 N / N_{\mathrm{Ex}}^{\prime}\right)} \leq f
\end{aligned}
$$

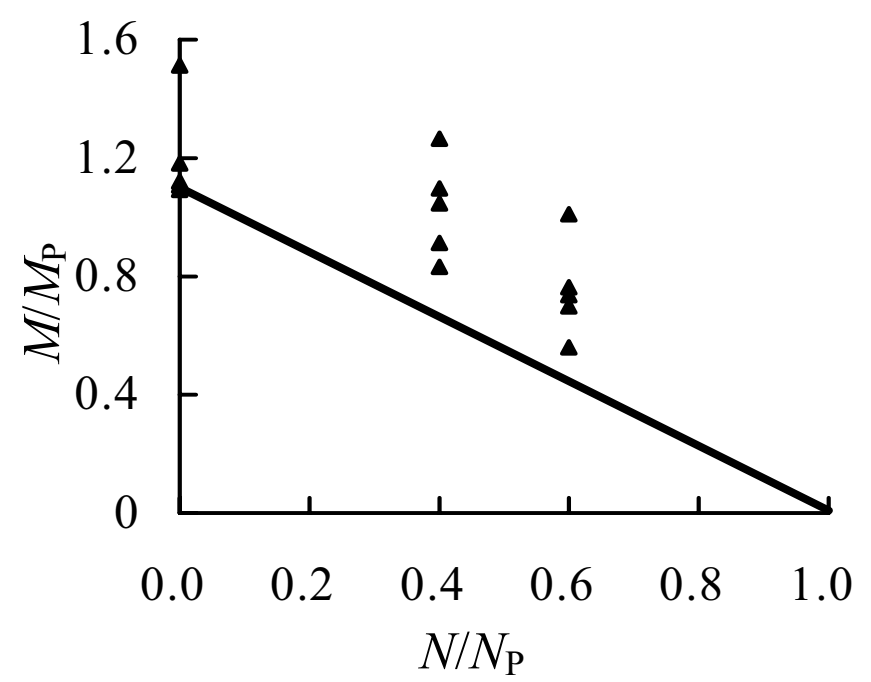

Figure 23. Interrelation of $M / M_{P}-N / N_{P}$

\section{CONCLUSIONS}

This paper has described a series of tests of steel beam-columns with box-section under cyclic bending. Three axial compression ratios were taken into account to investigate its influence, which was $0.0,0.3$, and 0.6 respectively, and five width-to-thickness ratios of plates were considered. Then the test results were present and analyzed. At the last part of this paper, the experimental results were compared with the numerical ones. The following conclusions could be made from this paper:

1. Beam-columns under cyclic bending might fail in fatigue fracture when no axial force presented, otherwise they might fail in cyclic plastic deformation and/or local buckling based on their width-to-thickness ratios of their plates and on the axial compression carried. 
2. The largest deformations generally located in the height of $b / 2 \sim b$ near the fix end according to test results.

3. By comparing the experimental and numerical results, the design formula was verified, and proved to be reasonable and could be used in practice.

\section{REFERENCES}

[1] Kato, B., "Inelastic bar subjected to thrust and cyclic bending", Journal of Structure Division, 1969, 95(1), pp.562-590.

[2] Toma, S. and Chen, W.F., "Cyclic analysis of fix-ended steel beam-columns", Journal of Structure Division, ASCE, 1982, 108(6), pp.1385-1399.

[3] Han, D.J. and Chen, W.F., "Buckling and cyclic inelastic analysis of steel tubular beam-columns", Engineering Structures, 1982, 5, pp.119-132.

[4] Ballio, G. and Calado, L., "Steel bent sections under cyclic loads: experiments and numerical approaches", Costruzioni Metalliche, 1986, 1, pp.2-24.

[5] Macrae, G.A., "Cyclic bending of steel I-shaped beam-columns", Proceeding of Pacific Structural Steel Conference, Brisbane, 1989.

[6] Watanable, E., "Modeling of hysteric behavior of thin-walled box members", Stability and Ductility of Steel Structures under Cyclic Loading. CRC press, 1992, pp.225-235.

[7] Hao, J.P., "Test and theoretical study on the local buckling and low cycles fatigue of steel structures under cyclic loading", PhD. thesis, School of Civil Engineering, Xi'an University of Architecture \& Technology, Xi' an, China, 1995 (in Chinese).

[8] Yamazaki, S. and Minami, S., "Inelastic behavior of steel beam-columns subject to varying axial force and cyclic bending moment", Proceeding of the 5th International Colloquium on Stability and Ductility of Steel Structures, Nagoya, Japan, 1997, pp.561-568

[9] Ohi, K., Chen, Y. and Takanashi, K., "An experimental study on inelastic behavior of H-shaped steel beam columns subject to varying axial and lateral load", Journal of Structure Engineering, Architecture Institute of Japan, 1996, 42B, pp.421-430.

[10] Miki, T. and Nethercot, D.A., "Cyclic instability of beam-columns with variable cross-section due to combination of collapse mechanisms", Proceeding of the 5th International Colloquium on Stability and Ductility of Steel Structures, Nagoya, Japan, 1997, pp.569-576.

[11] Gao, S.B., Usami, T. and Ge, H.B., "Eccentrically Loaded Steel Columns under Cyclic In-Plane Loading”, Journal of Structural Engineering, ASCE, 2000, 126(8), pp.964-973.

[12] Su, M.Z. and Gu, Q., "Study on Hysteretic Behavior of Box-section Steel Beam-columns under Cyclic Bending and on Limiting Ratio of Width-to-thickness of its Plates", Journal of Building Structures (in Chinese), 2000, 21(5), pp.41-47.

[13] Su, M.Z., Gu, Q. and Guo, B., "Finite Element Analysis of Steel Members under Cyclic Loading", Finite Elements in Analysis and Design, 2002, 39(4), pp.43-54. 